\title{
Effect of a dry purge step on the analysis by dynamic headspace - GC-MS of the volatile fraction of a cheese
}

\author{
D. Canac-Arteaga, C. Viallon, J.-L. Berdagué* \\ Laboratoire Flaveur, Station de Recherches sur la Viande, INRA de Theix, 63122 Ceyrat, France
}

\begin{abstract}
A dry purge procedure was used to eliminate water during the analysis of the volatile fraction of a water-rich cheese, by dynamic headspace-GC-MS. The impact of the duration of this procedure on chromatographic profile was studied for durations ranging from 0 to 50 minutes. A dry purge duration of 3 minutes sufficed to reduce the water peak area and improve the quality of the chromatographic signal. However, the dry purge procedure induced marked modifications to the chromatographic profile of the cheese throughout the range of component polarities.
\end{abstract}

Keywords. volatile compounds - cheese - purge-and-trap - dry purge - GC-MS.

\section{Introduction}

Dynamic headspace methods combined with gas phase chromatography and mass spectrometry are frequently used to characterize the volatile fraction of foodstuffs [1-7]. In dynamic headspace analysis, the volatile components are removed from the sample by purging with an inert gas and trapped on an adsorbent. However, the main volatile component extracted from foodstuffs is often water, which generates artefacts at the successive stages of the analysis [810]. These stages are: the trapping of the volatile components on the adsorbent, the thermal desorption of the volatile components, the concentration of the components at the capillary column head using a cooling system, the separation of the compounds in the capillary column, and the detection of the components.

A dry purge step inserted between trapping and desorption is a solution used by several instrument suppliers to limit injection of water into the capillary column. This procedure removes part of the water retained on the adsorbent during the volatile component trapping phase. This procedure is widely used, but no work has been published that clearly describes its impact on the analysis of the volatile fractions of water-rich samples.

The aim of the work reported here was to study the effect of water (i) on the analytical signal (baseline level, instrument noise, peak shape), and (ii) on the abundance of the different components present in the chromatographic profiles. For this purpose a cheese was analyzed, and dry purge durations ranging from 0 to 50 minutes were tested.

\section{Materials and Methods}

\section{Choice of the material to be analyzed}

To simplify sampling, a commercial wax-coated homogeneous pre-portioned hard processed cheese was selected (mini-babybel). This product is biochemically stable and has a volatile fraction that is relatively easy to study. Its water content is $48 \%$ and its water activity is 0.97 .

\section{Sample storage}

The cheeses in their wax packaging were wrapped in aluminum foil, vacuum sealed in polythene bags and stored at $-25^{\circ} \mathrm{C}$. Before each analysis of the volatile fraction, the sample was left overnight at ambient temperature.

\section{Purge and trap of volatile components by dynamic headspace}

The volatile components were extracted and trapped on an adsorbent using a Tekmar LSC 2000 purge-and-trap apparatus (Cincinnati, OH 45234, USA). $4 \mathrm{~g}$ of cheese diced into $3-\mathrm{mm}$ sided cubes were placed on glass fiber wool $\left(\mathrm{n}^{\circ} 23\right.$ 039.293 Prolabo) in the bottom of a glass extraction cartridge (height: $70 \mathrm{~mm}$, outside diameter: $34 \mathrm{~mm}$ ). The cartridge was swept by a stream of helium $\mathrm{N}_{45}$ (purity 99.995\%, Air Liquide) at a flow rate of $60 \mathrm{ml} \cdot \mathrm{min}^{-1}$. Purging at $19{ }^{\circ} \mathrm{C}$ took 20 minutes (step 1, figure 1). The adsorbent used was Tenax, $0.29 \mathrm{~g}, 60 / 80$ mesh, length $24 \mathrm{~cm}$, inside diameter $1 / 8$ inch ( $\mathrm{n}^{\circ}$ 2-1059-U, Supelco) operating at $30^{\circ} \mathrm{C}$. 


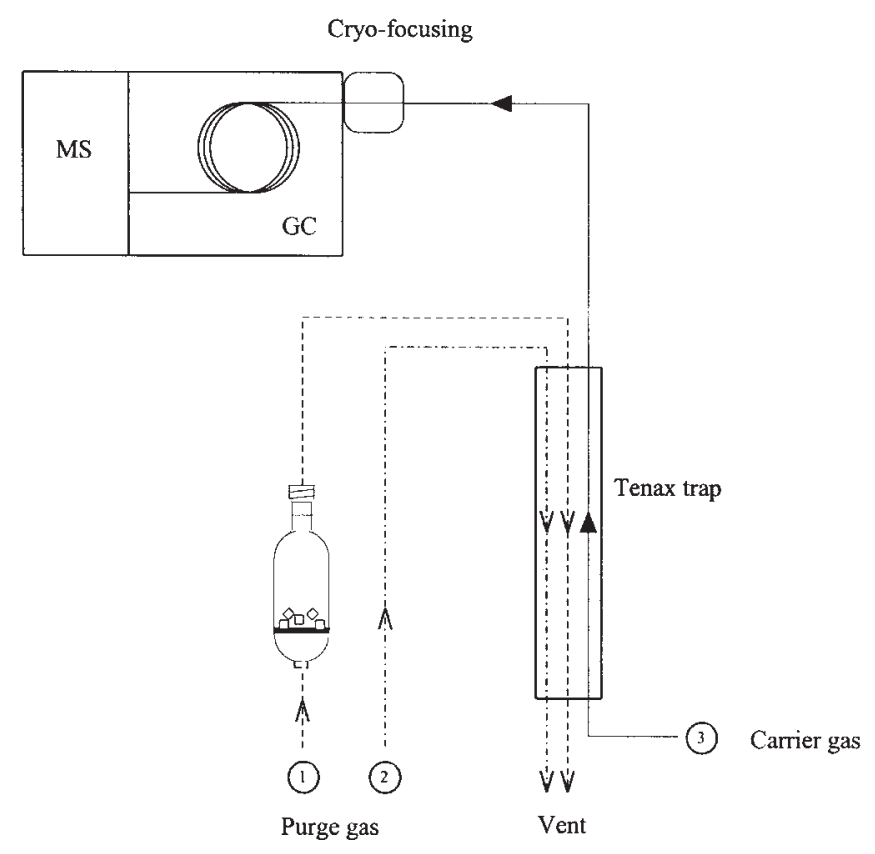

Fig. 1. Schematic diagram of the circuit for the analysis of volatile compounds by dynamic headspace coupled with gas chromatography - mass spectrometry.

(1) Purge of the volatile compounds and trapping on Tenax adsorbent

(2) Dry purge circuit

(3) Desorption of the volatile compounds trapped on the Tenax. After desorption the volatile compounds are cryo-focused at $-150{ }^{\circ} \mathrm{C}$ and injected by heating in the capillary column

\section{Elimination of the water retained on the adsorbent by the dry purge method}

This helium drying operation (step 2, figure 1) eliminates some of the water retained on the Tenax during the trapping of the volatile components. Seven experiments were conducted with dry purge durations of $0,3,7,10,20,30$ and 50 minutes with a flow rate of helium $\mathrm{N}_{45}$ set at $60 \mathrm{ml} \cdot \mathrm{min}^{-1}$.

\section{Injection of the volatile components into the capillary column}

The volatile components were simultaneously desorbed from the Tenax at $180^{\circ} \mathrm{C}$ for 5 minutes using a carrier gas helium $\mathrm{N}_{55}$ (purity $99.9995 \%$, Air Liquide) with a flow rate of $1.4 \mathrm{ml} \cdot \mathrm{min}^{-1}$, and cryo-focused at $-150^{\circ} \mathrm{C}$ in a $3-\mathrm{cm}$ segment of deactivated silica pre-column (inside diameter: $0.53 \mathrm{~mm}$, length: $1.5 \mathrm{~m}$, Varian) using a liquid nitrogen cooling system (step 3, figure 1). Injection into the capillary column was then carried out by heating the precolumn for 2 minutes at $225^{\circ} \mathrm{C}$. To eliminate any potential memory effects between successive analyses, the Tenax trap was then heated for 20 minutes at $180^{\circ} \mathrm{C}$.

\section{Separation, detection and identification of the volatile components}

The volatile components were separated on a capillary column (SPB5, film thickness: $1 \mu \mathrm{m}, 60 \mathrm{~m} \times 0.32 \mathrm{~mm}$; Supelco). The oven temperature of the chromatograph (Hewlett Packard 5890) was programmed as follows: 5 minutes at $33{ }^{\circ} \mathrm{C}$, then to $200{ }^{\circ} \mathrm{C}$ at $3{ }^{\circ} \mathrm{C}$ per minute, and finally 2 minutes at $200{ }^{\circ} \mathrm{C}$. The volatile components were detected by mass spectrometry with electron impact at $70 \mathrm{eV}$ (Hewlett Packard 5971S). Acquisition was 3 scans.s $^{-1}$ with a scanning range from 15 to 190 daltons between 0 and 60 minutes. The volatile compounds were identified by comparing their spectra with those in the data bank NBS $75 \mathrm{~K}$ (1994), and their retention indices with those in the data bank of Kondjoyan and Berdagué, 1996 [11].

\section{Evaluation of the quality of the baseline and calculation of the chromatographic peak areas}

The baseline level (expressed in arbitrary abundance units) was measured between 48 and 50 minutes in a peak-free segment. To account for the noise in this chromatogram segment an average spectrum was calculated. The peak areas of the volatile compounds (arbitrary units of area, a.u.a.) were integrated from specific ions of each molecule to circumvent coelution problems (these ions are not stated here in view of the very large numbers of compounds involved). The integrations were carried out using MSD ChemStation software (Hewlett Packard). The integration parameters were as follows: initial detection threshold: 8 a.u.a.; initial peak width: 0.2 minutes; minimum peak area: 10,000 a.u.a.

\section{Statistical analysis}

The effect of the duration of dry purge on the chromatographic profiles was studied by principal component analysis performed on normalized and standardized data (Statistica, 1997).

\section{Results}

The chromatographic profile of the cheese studied (Fig. 2) comprised 27 peaks, of which the strongest were 3-hydroxy2-butanone, 2,3-butanedione, 2-butanone, and acetone.

The duration of the dry purge highly influenced the area (Fig. 3A) and the shape (Fig. 3B and C) of the water peak. Thus the area of the water peak decreased from 67,000 to 3,000 a.u.a. after only 3 minutes of dry purge (figure $3 \mathrm{~A}$ ). With no dry purge the water peak was very broad (from 4 to 30 minutes) and had a complex shape with three sharp breaks coinciding with the successive elution peaks of acetone, 2,3-butanedione and 3-hydroxy-2-butanone (Fig. 3B). Also, most of the polar constituents coeluted with water between 5 and 20 minutes had flat and unsymmetrical peaks (broadening and multimodality in the case of ethanol).

The variations in peak area of all the compounds according to the dry purge duration were studied by principal 


\section{Original articles}

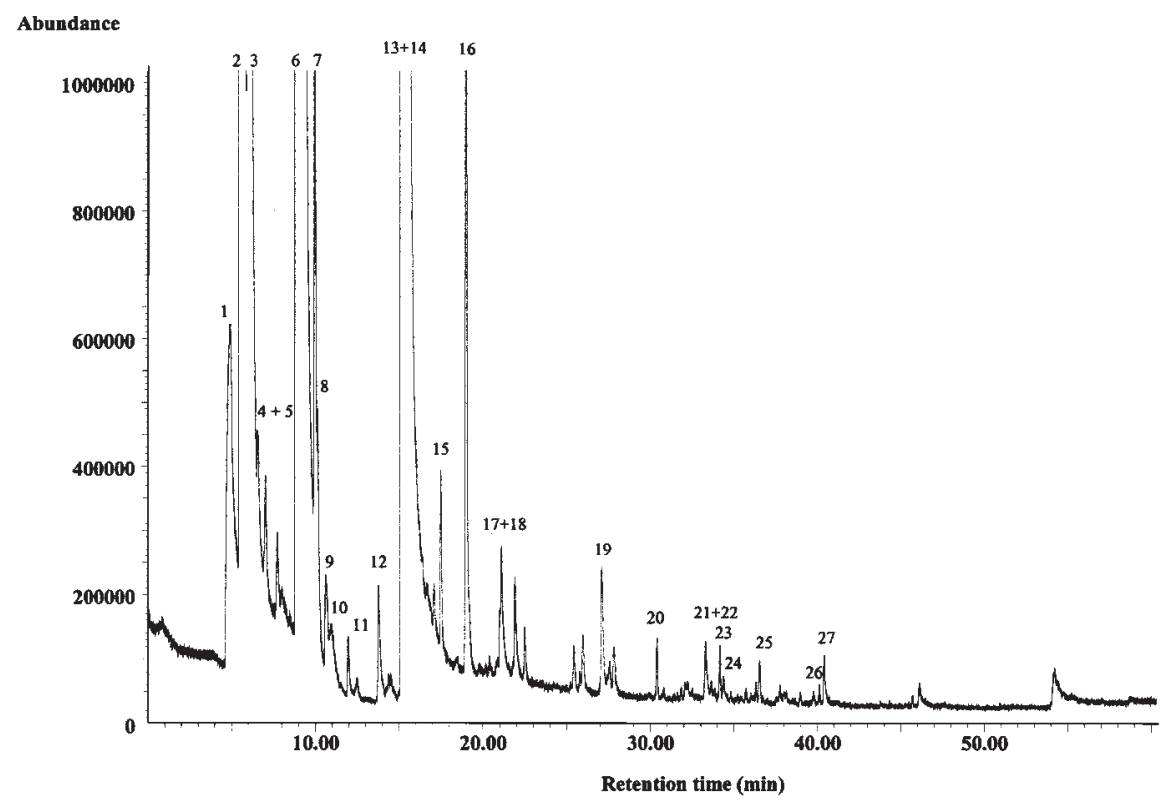

Fig. 2. Example of chromatographic profile of cheese obtained by dynamic headspace GC-MS with a dry purge of 3 minutes. The compounds identified were the following in order of elution (the number in brackets represents the percentage of the peak in the total ion current of the chromatogram): $1=$ water $(1 \%), 2=$ ethanol $(4.6 \%), 3=$ acetone $(4 \%), 4=2$-propanol $(0.13 \%), 5=$ dimethyl sulfide $(0.11 \%), 6=2,3$-butanedione $(7.4 \%), 7=2$-butanone $(11 \%), 8=2$-butanol $(0.62 \%), 9=$ acetic acid $(0.01 \%), 10=$ ethyl acetate $(1 \%)$, $11=3$-methyl butanal $(0.05 \%), 12=2$-pentanone $(0.3 \%), 13=3$-hydroxy-2-butanone $(68.4 \%), 14=$ propyl acetate $(0.25 \%)$, $15=$ dimethyl disulfide $(0.14 \%), 16=$ toluene $(0.66 \%), 17=$ hexanal $(0.06 \%), 18=$ octane $(0.05 \%), 19=2$-heptanone $(0.06 \%)$, $20=\alpha$-pinene $(0.03 \%), 21=\beta$-pinene $(0.01 \%), 22=6$-methyl-5-hepten-2-one $(0.08 \%), 23=$ decane $(0.02 \%), 24=$ octanal $(0.02 \%)$, $25=$ limonene $(0.02 \%), 26=2$-nonanone $(0.01 \%), 27=$ nonanal $(0.03 \%)$.

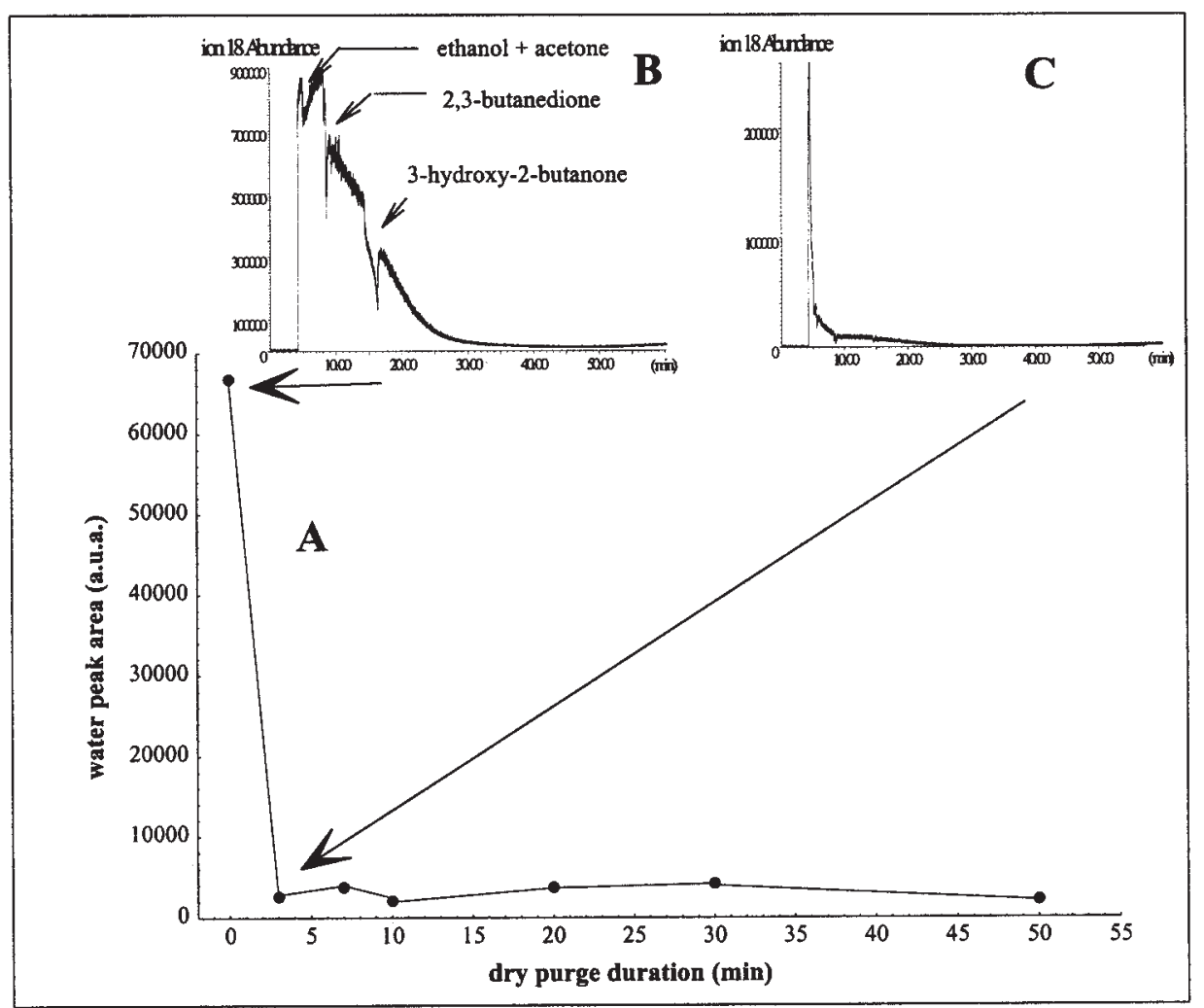

Fig. 3. Water peak area and shape versus dry purge duration.

A: Water peak area versus dry purge duration.

B: Abundance of ion 18 (water) without dry purge.

C: Abundance of ion 18 with a dry purge of 3 minutes. 
component analysis (Fig. 4). The principal interest of this analysis was to show that the areas of the different chromatographic components changed in a complex way according to the dry purge duration. Furthermore this analysis showed that a priori it doesn't exist an obvious rule in order to explain the effect of the dry purge. The volatile components were distributed into two groups in the main PCA plane. The first group comprised the compounds that had the greatest peak areas without dry purge (polar molecules: ethanol, acetone, propyl acetate, propanol, etc. and nonpolar molecules: beta-pinene, octane, decane, etc.). The second group comprised compounds that had greater peak areas when the dry purge duration was long (2,3-butanedione, 2pentanone, limonene, dimethyldisulfide, ethyl acetate, etc.). Figure 5 shows the quantitative changes in the peak areas of three compounds belonging to either of these two groups, according to the dry purge duration.

The study of the analytical noise and baseline level also showed a strong water effect. With no dry purge the noise of the signal associated with ion 18 was very strong between 4 and 30 minutes, during the elution time of the water peak (Fig. 3B). A 3-minute dry purge considerably lowered the baseline (Fig. 6A) and thereby the noise (Fig. 6B and C). The detailed analysis of the noise without dry purge (Fig. 6B) shows that it included all the ions of the main volatile compounds of the cheese, together with the ions characteristic of silylated radicals $(\mathrm{m} / \mathrm{z}=73,75,103,133)$, benzene structures $(\mathrm{m} / \mathrm{z}=119,77,177)$ and phtalates $(\mathrm{m} / \mathrm{z}=147)$. With a dry purge (Fig. 6C), the noise was less marked and corresponded essentially to ions of molecular weight 43, 45, 60, 77 and 86 daltons.

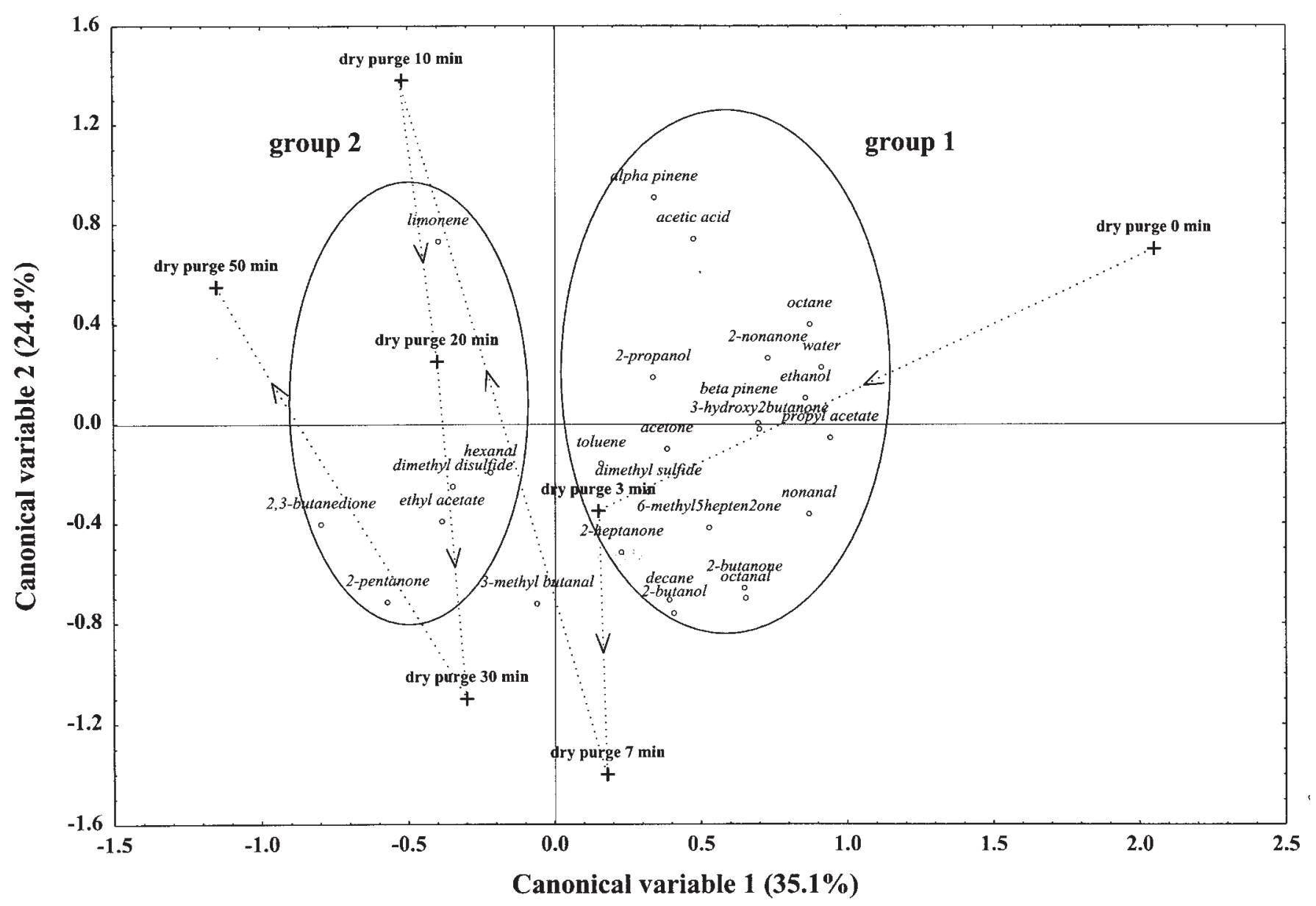

Fig. 4. Principal component analysis with 27 variables (volatile compounds of cheese) and 7 observations (duration of the dry purge step). The plane $(1,2)$ explains $59.5 \%$ of total variance.

The progression in dotted line between the 7 observations (from "dry purge 0 min" to "dry purge 50 min") shows that the volatile compounds evolve in a complex way according to the dry purge duration.

The volatile compounds are distributed into 2 groups:

Group 1: volatile compounds with higher abundance without dry purge.

Group 2: volatile compounds with higher abundance when dry purge duration was longer. 


\section{Original articles}

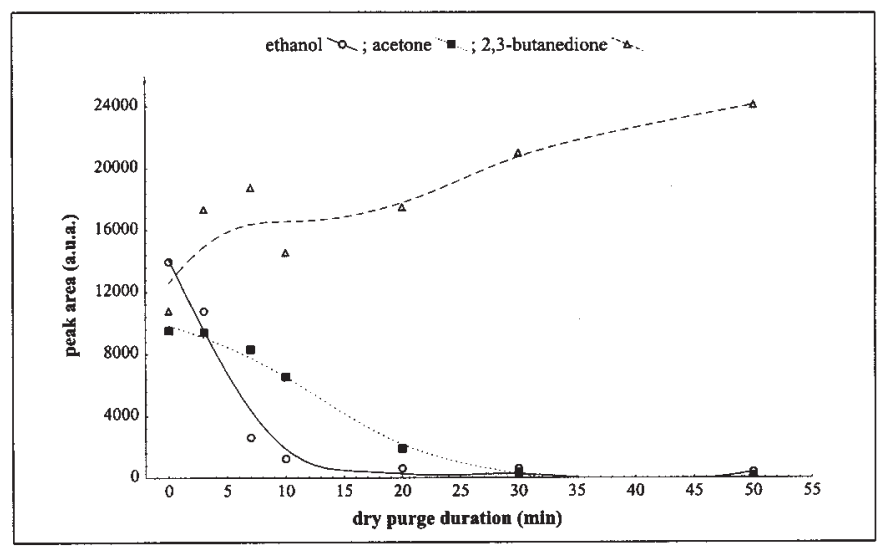

Fig. 5. Peak areas of ethanol, acetone and 2,3-butanedione versus dry purge duration.

\section{Discussion}

The effect of the dry purge on the GC-MS measurements are due to multiple physical, chemical and mechanical interactions between water, the volatile components, the adsorbent, the pre-column and the capillary column. These interactions, in which water is strongly implicated, disturb all the steps of the analysis, impairing the quality of the measurements unless a dry purge is used.

In the trapping stage, competition in adsorption-desorption between water and the other volatile components occurs at the surface of the Tenax. Hence for samples containing much water (such as the cheese here) a large proportion of the adsorption sites in the trap are occupied by water molecules in the first minutes of the trapping step, despite the low affinity of Tenax for these molecules. When the trap is saturated with water, water is no longer retained, and it carries away polar volatile components with which it forms hydrogen bonds.

In the dry purge step a large proportion of the water is eliminated from the trap, causing the desorption of molecules of ranging polarity. The mechanisms of desorption involve water-volatile component, water-Tenax, and volatile component-Tenax interactions. These mechanisms account for the behavior of the volatile components of group 1 (Fig. 4), whose peak areas decrease as the dry purge duration increases. However, they cannot explain the behavior of the volatile components in group 2, whose peak areas increase with the dry purge duration, because in the purgeand-trap step the quantities adsorbed on the Tenax are the same regardless of the dry purge duration.

During the desorption from the trap at $180{ }^{\circ} \mathrm{C}$, water and the volatile components can chemically degrade the polymer structure of the 2,6-diphenyleparaphenylene oxide elements of the Tenax, which would explain the presence of ions characteristic of benzene structures found during noise analysis without dry purge. After migration in the pre-column, the

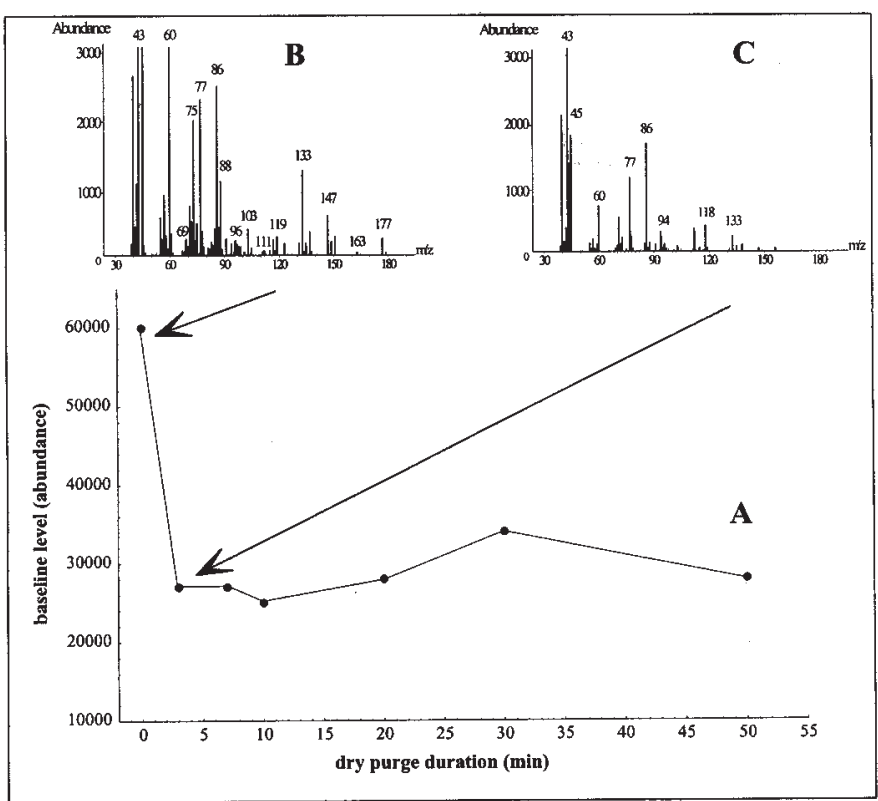

Fig. 6. Baseline level and baseline noise.

A: Baseline level versus chromatographic duration.

B: Abundance of ions present in the baseline noise without dry purge.

C: Abundance of ions present in the baseline noise with a dry purge of 3 minutes.

volatile components desorbed from the trap will be concentrated in the cryo-focusing segment. According to the quantities of water desorbed from the trap this pre-column segment can be totally or partially obstructed by ice. In our analyses, total obstruction preventing the complete desorption of the volatile components of the Tenax can be ruled out, because the helium flow rate in the chromatography column did not vary during the cryo-focusing step (the pressure in the ionization chamber of the mass spectrometer was stable). According to Kostiainen [12] partial obstruction by ice of the pre-column and the resulting local reduction in its inside diameter causes a local increase in the velocity of the carrier gas and thereby reduces the efficiency of the cryofocusing of the volatile components. In some cases the efficiency of the cryo-focusing can interact with the dry purge duration. The quantity of ice in the cryo-focusing segment is directly linked to the quantity of water and volatile components desorbed from the Tenax trap. As the dry purge duration increases, the quantity of water and volatile components retained on the Tenax trap decreases, and so the quantity of ice deposited in the pre-column during the desorption from the trap also decreases. Some components can then be better focused in the cryofocusing segment for the reasons stated above by Kostiainen, which would afford an explanation for the behavior of the compounds in group 2 (Fig. 4), whose abundance increases with the dry purge duration. 


\section{Original articles}

Injection by vaporization of the water and the volatile components into the capillary column is achieved by rapid reheating of the pre-column to $225^{\circ} \mathrm{C}$. Given that the temperature of the column is $33^{\circ} \mathrm{C}$, the water and the volatile components condense at the column head. This condensation is greater if there is no dry purge, and will take place along a segment several meters long, and even form a meniscus in extreme cases. During the condensation phase, the polar components and the water form an azeotrope, and their injection into the column is poorly focused, which explains the peak broadening observed without dry purge. This broadening is particularly marked for the major volatile components of cheese because the main fragments of these compounds (ethanol: $\mathrm{m} / \mathrm{z}=45$; acetone: $\mathrm{m} / \mathrm{z}=43$; 2,3-butanedione: $\mathrm{m} / \mathrm{z}=43,86 ;$ 2-butanone: $\mathrm{m} / \mathrm{z}=43$; acetic acid: $\mathrm{m} / \mathrm{z}=43,45,60$ et 3-hydroxy-2-butanone: $\mathrm{m} / \mathrm{z}=43$, $45,88)$ make up a large proportion of the baseline noise when there is no dry purge (Fig. 6B). The occurrence of multimodalities for polar compounds such as water and ethanol is due to complex interactions between water, the nonpolar chromatographic phase and the volatile components (ethanol, acetone, 2,3-butanedione and 3-hydroxy-2butanone). These interactions involve both hydrophilic bonds (hydrogen bonds) and hydrophobic bonds (Van Der Waals and electrostatic interactions). The notable presence of silylated radicals in the total ion current (Fig. 6B) is due to a massive inflow of water in the capillary column, which degrades the methyl-phenyl silicone phase.

\section{Conclusion}

This study clearly demonstrates the effect of dry purge on the qualitative and quantitative results of the dynamic headspace-GC-MS analysis of the volatile fraction of a cheese.
A detailed analysis of the results suggests several explanations for the impact of water on the successive steps of the analysis, which were lacking in the literature. These explanations take into account physical, chemical and mechanical interactions between the water, the volatile components, the adsorbent, the pre-column and the capillary column.

Finally, the use of a dry purge improves chromatographic quality (marked reduction of analytical noise, broadening and multimodality of polar peaks), but modifies the proportions of the different components in the chromatographic profile in a complex way.

\section{References}

1. Bosset, J. O.; Gauch, R. Int. Dairy Journal 1993, 3, 359-377.

2. Christensen, T. C.; Hølmer, G. Milchwissenschaft 1996, 51 (3), 134-138.

3. Heikes, D. L.; Jensen, S. R.; Fleming-Jones, M. E. J. Agric. Food Chem. 1995, 43, 2869-2875.

4. Malundo, T. M. M.; Baldwin, E. A.; Moshonas, M. G.; Baker, R. A.; Shewfelt, R. L. J. Agric. Food Chem. 1997, 45, 21872194.

5. Mateo, J.; Zumalacarregui, J. M. Meat Sci. 1996, 44, 255-273.

6. Narain, N.; Hsieh, T. C.-Y.; Johnson, C. E. J. Food Sci. 1990, 55, 1303-1307.

7. Ott, A.; Fay, L. B.; Chaintreau, A. J. Agric. Food Chem. 1997, $45,850-858$.

8. Helmig, D.; Vierling, L. Anal. Chem. 1995, 67, 4380-4386.

9. Hinshaw, J. V. LC-GC International 1990, 3, 22,24-26.

10. Pankow, J. F. Environ. Sci. Technol. 1991, 25, 123-126.

11. Kondjoyan, N.; Berdagué, J.L. A compilation of relative retention indices for the analysis of aromatic compounds; laboratoire flaveur, Ed.; Clermont-Ferrand; 1996.

12. Kostiainen, R. Chromatographia 1994, 38, 709-714. 